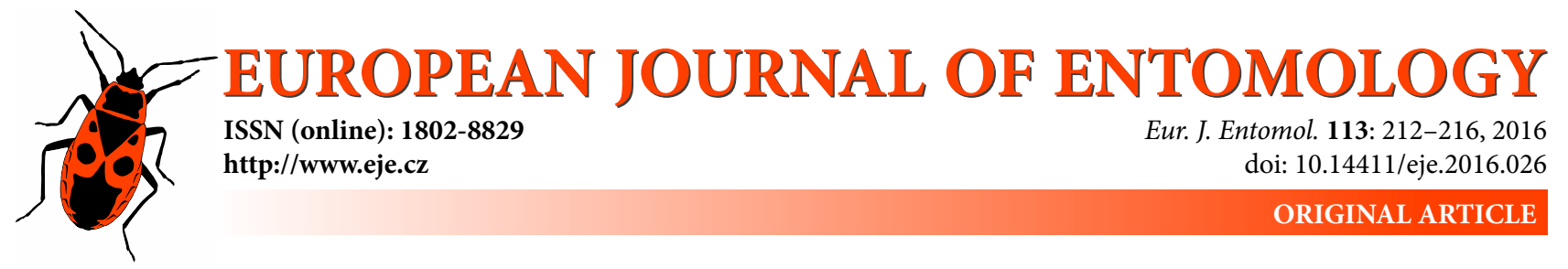

\title{
Effect of three species of host tree on the cold hardiness of overwintering larvae of Anoplophora glabripennis (Coleoptera: Cerambycidae)
}

\author{
YuQIAN FENG ${ }^{1}$, REAXIt TURSUN ${ }^{1}$, ZHICHUN XU $^{1}$, FANG OUYANG ${ }^{2, *}$ and SHIXIANG ZONG ${ }^{1, *}$ \\ ${ }_{1}^{1}$ Beijing Key Laboratory for Forest Pest Control, Beijing Forestry University, Beijing, 100083, P. R. China; \\ e-mails: fengyuqian1988@163.com, 1064253317@qq.com, zhchxu@bjfu.edu.cn, zongsx@126.com \\ ${ }^{2}$ State Key Laboratory of Integrated Management of Pest and Rodents, Institute of Zoology, Chinese Academy of Sciences, \\ Beijing 100101, China; e-mail: ouyangf@ioz.ac.cn
} Key words. Coleoptera, Cerambycidae, Anoplophora glabripennis, overwintering larvae, host trees, supercooling point,
physiological and biochemical substances

\begin{abstract}
The Asian long-horned beetle, Anoplophora glabripennis, is a serious destructive pest of forests throughout China as it attacks a wide range of host plants. The effect of host trees on the cold hardiness of $A$. glabripennis larvae could be the basis for predicting the performance of this forest pest on different common hosts. To evaluate the effect of different species of host plant on the cold hardiness of overwintering larvae of $A$. glabripennis, we measured the supercooling point (SCP), fresh mass, protein content and concentrations of low molecular weight substances in overwintering larvae collected from three different host species (i.e., Populus opera, Populus tomentosa and Salix matsudana). Mean SCPs and protein contents of larvae from these three hosts differed significantly. The SCPs and protein contents of the larvae collected from $P$. opera and $P$. tomentosa were significantly higher than those collected from S. matsudana. The concentrations of glycerol, glucose and trehalose in overwintering larvae collected from these host species also differed significantly, but there were no significant differences in the concentrations of sorbitol and inositol. The larvae that were collected from S. matsudana had the highest concentrations of glycerol and trehalose and those from $P$. opera the lowest contents of glycerol, whereas those from $P$. tomentosa had the lowest concentrations of trehalose but the highest concentrations of glucose. Because of the significant differences in the quantities of these biochemical substances in their bodies, the cold hardiness of overwintering larvae of $A$. glabripennis was significantly dependent on the tree they fed on. These effects on the cold hardiness of the overwintering larvae might affect the selection of a host tree and therefore the spread of this beetle.
\end{abstract}

\section{INTRODUCTION}

The cold hardiness of insects is associated with genetically based traits and is also closely correlated with their physiological status, external environment, developmental stage and water content. Other factors also have important effects on cold resistance, including the composition of cold resistant materials, active ice-nucleation, host plant, temperature and humidity, and latitude, among others (Jing \& Kang, 2002; Danks, 2006; Li et al., 2008). Before overwintering, phytophagous insects store energy by feeding on a wide variety of host plants (Sakurai et al., 1992; Zhong et al., 2009). After feeding on different host plants, many changes occur in the metabolic processes that affect the concentrations of glycogen, lipids, moisture, glycerol and low molecular weight substances, and these changes in physiological and metabolic processes affect the cold hardiness of insects (Hunter \& McNeil, 1997). In different seasons, the availability, variety and quality of host plants differ, which affects the growth rate, survival and fecundity, among many other factors, of insects. As a consequence, the developmental stages of insects that overwinter differ, as do their survival (Hunter \& McNeil, 1997). For example, the supercooling points (SCPs) of Phyllotreta undulata beetles reared on white mustard, Indian mustard, white cabbage and oilseed rape are $-9.6^{\circ} \mathrm{C},-10.9^{\circ} \mathrm{C}$, $-14.5^{\circ} \mathrm{C}$ and $-13.5^{\circ} \mathrm{C}$, respectively (Hiiesaar et al., 2009), and the overwintering survival of Chrysomela lapponica beetles that feed on willow trees from different areas differ significantly (Zvereva, 2002). Furthermore, diapause and cold resistance of Helicoverpa armigera larvae reared on ordinary cotton or Bt cotton differ significantly (Ouyang et al., 2011).

The Asian long-horned beetle, Anoplophora glabripennis (Coleoptera: Cerambycidae), is one of the most impor-

\footnotetext{
* Corresponding authors; e-mails: zongsx@126.com, ouyangf@ioz.ac.cn
} 
tant pests of forests throughout China (Qin \& Jin, 1959). The larvae bore into and feed on the trunk of the tree causing serious damage to the conducting tissues of the host, which results in the death of large branches. The beetles can kill trees, which eventually leads to a reduction in the productivity of forested lands and enormous economic loss (Hu et al., 2009). In China, the life cycle of A. glabripennis is one to two years long. The larvae overwinter inside the trunks of trees in most areas, although eggs or pupae overwinter in a few areas (Luo \& Li, 1999). Currently, this beetle is recorded feeding on 18 genera of plants, including Populus, Salix, Ulmus and Acer (Luo \& Li, 1999). The 3 species of trees, Populus opera, Populus tomentosa and Salix matsudana are the most common hosts and widely distributed. In addition, the damage caused by $A$. glabripennis to these three host trees has changed in recent years. The ability of the larvae to overwinter in different hosts is an important factor that affects $A$. glabripennis populations the following year. The effects of different species of host tree on the cold hardiness of overwintering larvae of $A$. glabripennis, however, remain to be investigated.

In this paper, the focus of the research is on larvae of A. glabripennis that fed and overwintered on $P$. opera, $P$. tomentosa and S. matsudana, respectively. The SCP, fresh mass, protein content and concentrations of low molecular weight substances in overwintering larvae were measured and used to compare their cold hardiness. Understanding the effect that different host plants have on the overwintering of A. glabripennis larvae will help determine the cause of outbreaks and how they can be controlled, and provide a solid foundation for the effective control of this beetle.

\section{MATERIALS AND METHODS}

\section{Insect}

In July 2012, P. opera (mean height and diameter approximately $9 \mathrm{~m}$ and $10 \mathrm{~cm}$, respectively) and $S$. matsudana (approximately $5 \mathrm{~m}$ and $8 \mathrm{~cm}$, respectively) were used to raise A. glabripennis in the field. These trees were in a farmland shelterbelt in Lingwu City $\left(38^{\circ} 19^{\prime} \mathrm{N}, 106^{\circ} 26^{\prime} \mathrm{E}\right)$, Ningxia Hui Autonomous Region. The trunks of the host trees were ringed with a wire cage (approximately $1.0-1.5 \mathrm{~m}$ ) approximately $1.5-3 \mathrm{~m}$ above the ground. The adults were first collected in the field in Yanchi City in the middle of July and placed inside the wire cage on each trunk in the proportion of $1: 1$ male to female. Approximately 20-30 pairs of A. glabripennis were caged on each tree to lay eggs and produce offspring. The larvae that had fed on $P$. tomentosa were collected from a natural $P$. tomentosa forest in Yanchi City $\left(37^{\circ} 78^{\prime} \mathrm{N}\right.$, $\left.107^{\circ} 22^{\prime} \mathrm{E}\right)$, Ningxia Hui Autonomous Region. The different species of brood trees were transported to a laboratory at Beijing Forestry University during January 2014. The overwintering larvae were removed from the brood trees and maintained in $10 \mathrm{ml}$ transparent test tubes at outdoor temperatures. Holes were made in the walls of the tubes using an electric iron to ensure an adequate air supply. The larvae collected from each host species were the ones used in this study.

The head widths of larvae collected from $P$. opera ranged between 3.80 and $5.08 \mathrm{~mm}$, from P. tomentosa between 3.88 and 4.88 and from $S$. matsudana between 3.37 and $4.88 \mathrm{~mm}$. As previously it was the head widths of fourth and fifth-instar overwintering larvae that were measur (He \& Huang, 1992).

\section{Determination of SCP and FP}

Before determining the SCP the body temperature of the larvae was rapidly reduced by placing them in a box full of an icewater mixture. Each larva was attached by parafilm to the tip of a thermocouple, which was linked to an automatic data recorder (SCP measuring instrument). With the thermocouple attached and surrounded by absorbent cotton, each larva was placed into a freezing chamber (high-low temperature test chamber); the temperature in this chamber was reduced from $20^{\circ} \mathrm{C}$ to $-30^{\circ} \mathrm{C}\left(1{ }^{\circ} \mathrm{C} /\right.$ $\mathrm{min})$; and the body temperature of the larva recorded. A physical phenomenon, supercooling occurs when aqueous solutions (or various aqueous systems) remain liquid. The SCP is the instantaneous temperature recorded when the body fluids of an insect begin to freeze. At this point, the body temperature suddenly increases because of the emission of latent heat of crystallization; the SCP is the flex point and is recorded by the thermocouple and computer. The SCPs of 10-20 larvae collected from each species of host tree were measured.

\section{Measurement of fresh mass}

To measure the fresh weight of larvae from each species of host tree, 14-34 larvae were selected. The fresh mass of each larva was determined three times using an electronic balance $( \pm 0.001 \mathrm{~g})$.

\section{Measurement of physiological and biochemical substances}

\section{Measurement of low molecular weight substances}

The determination of low molecular weight substances was based on the method reported by Feng et al. (2014). From each of five individuals from the same species of tree, $100 \mu \mathrm{L}$ of hemolymph was extracted and mixed with $0.4 \mathrm{ml}$ of $79 \%$ ethanol (including $10 \mathrm{~g}$ of erythritol as an internal standard) in $2 \mathrm{ml}$ Eppendorf tubes. After centrifugation twice at $10,000 \mathrm{~g}$ for $5 \mathrm{~min}$, the extracted supernatant was stored at $-20^{\circ} \mathrm{C}$ until analyzed. In the pre-analytical phase, the sample liquids were evaporated to dryness using nitrogen at $40^{\circ} \mathrm{C}$. The dried samples were dissolved in $1.0 \mathrm{ml}$ of pyridine. A mixture of hexamethyldisilazane and chlorotrimethylsilane was added to an ice-water bath, which stood for $30 \mathrm{~min}$ at $20^{\circ} \mathrm{C}$. After high-speed centrifugation, $1.0 \mu \mathrm{l}$ of the supernatant was directly injected into a Meteorological Chromatography Detector (Agilent 7890 GC, America) to analyze the components. The components and the concentrations of the low molecular weight substances were determined based on comparisons with the peak times and areas of five different concentrations of a standard that ranged from 0 to $1.0 \mu \mathrm{g} / \mu \mathrm{l}$ in incremental steps of $0.2 \mu \mathrm{g} / \mu \mathrm{l}$.

\section{Measurement of protein content}

From the larvae, $10 \mu \mathrm{l}$ of hemolymph fluid was extracted and mixed with $10 \mu \mathrm{l}$ of PBS in Eppendorf tubes. The supernatant was collected after centrifugation at 3,000 g for $10 \mathrm{~min}$. To measure protein content, $2 \mathrm{ul}$ of protein extract was analyzed in an ND2000 (NanoDrop 2000, USA) at $595 \mathrm{~nm}$. For each group this was replicated three times.

\section{Statistical analyses}

The statistical analyses of all data were performed using SPSS statistical software package version 18.0 for Windows. One-way analysis of variance (ANOVA) and least significant difference tests (LSD, $\alpha=0.05$ ) were used to test the differences in SCP, fresh mass, protein content and concentrations of low molecular weight substances in the larvae collected from the three species of host tree. Linear regression was used to test the relationships between SCP and the physiological and biochemical substances in the overwintering larvae. 
Table 1. Supercooling point $\left({ }^{\circ} \mathrm{C}\right)$ of overwintering larvae collected from three species of trees.

\begin{tabular}{lcccc}
\hline Host tree & Number & $\begin{array}{c}\text { Mean } \pm \mathrm{SE} \\
\left({ }^{\circ} \mathrm{C}\right)\end{array}$ & $\begin{array}{c}\text { Maximum } \\
\left({ }^{\circ} \mathrm{C}\right)\end{array}$ & $\begin{array}{c}\text { Minimum } \\
\left({ }^{\circ} \mathrm{C}\right)\end{array}$ \\
\hline P. opera & 10 & $-9.04 \pm 0.85 \mathrm{a}$ & -5.00 & -13.40 \\
P. tomentosa & 10 & $-13.39 \pm 1.34 \mathrm{~b}$ & -8.70 & -22.30 \\
S. matsudana & 20 & $-16.02 \pm 1.08 \mathrm{~b}$ & -7.90 & -26.70 \\
\hline
\end{tabular}

Values followed by different letters within a column are significantly different $(P<0.05)$.

\section{RESULTS}

\section{SCP}

The SCPs of the overwintering larvae that were collected from the three species of host tree differed significantly $(\mathrm{F}$ $=8.92 ; \mathrm{df}=2,39 ; \mathrm{P}=0.001$; Table 1$)$. The larvae collected from $S$. matsudana had the lowest SCP $(-16.02 \pm$ $1.08^{\circ} \mathrm{C}$ ) and those collected from $P$. opera the highest SCP, both of which were significantly higher than that of the larvae from the other host tree $\left(\mathrm{P}_{1}=0.029 ; \mathrm{P}_{2}<0.001\right)$. The SCPs of larvae collected from the three species of host trees differed from one another, and the difference between the maximum and the minimum value was $8^{\circ} \mathrm{C}$. In general, the supercooling capacity of overwintering larvae from the three trees was ranked as follows: $P$. opera $<P$. tomentosa $<$ S. matsudana.

\section{Fresh mass}

In terms of fresh mass the overwintering larvae from the three species of trees were significantly different $(\mathrm{F}=4.15$; $\mathrm{df}=2,61 ; \mathrm{P}=0.021$; Table 2). The fresh mass of overwintering larvae collected from $P$. opera was significantly lower than that of those from the other two host species $\left(\mathrm{P}_{1}\right.$ $\left.=0.012 ; \mathrm{P}_{2}=0.008\right)$. However, there were no significant differences in the fresh mass of the larvae from $P$. tomentosa and S. matsudana, which had a fresh mass of approximately $1.55 \mathrm{~g}$.

\section{Concentration of low molecular weight substances}

Glycerol, glucose, sorbitol, trehalose and inositol were identified in the hemolymph of overwintering larvae. The concentrations of glycerol $(\mathrm{F}=6.51 ; \mathrm{df}=2,8 ; \mathrm{P}=0.030)$, glucose $(\mathrm{F}=5.93 ; \mathrm{df}=2,8 ; \mathrm{P}=0.004)$ and trehalose $(\mathrm{F}$ $=5.21 ; \mathrm{df}=2,8 ; \mathrm{P}=0.049)$ in the hemolymph of overwintering larvae from the three species of trees differed significantly (Table 3 ). The concentrations of glycerol and trehalose in the overwintering larvae from $S$. matsudana were the highest, whereas the glycerol content of those from $P$. opera $(26.58 \pm 1.18 \mu \mathrm{g} / \mu \mathrm{l})$ was significantly lower than that of those from $P$. tomentosa and S. matsudana $\left(\mathrm{P}_{1}\right.$
Table 2. Fresh mass (g) of overwintering larvae collected from three species of trees.

\begin{tabular}{lcccc}
\hline Host tree & Number & $\begin{array}{c}\text { Mean } \pm \text { SE } \\
(\mathrm{g})\end{array}$ & $\begin{array}{c}\text { Maximum } \\
(\mathrm{g})\end{array}$ & $\begin{array}{c}\text { Minimum } \\
(\mathrm{g})\end{array}$ \\
\hline P. opera & 14 & $1.14 \pm 0.11 \mathrm{a}$ & 1.97 & 0.62 \\
P. tomentosa & 14 & $1.57 \pm 0.13 \mathrm{~b}$ & 2.44 & 0.69 \\
S. matsudana & 34 & $1.55 \pm 0.08 \mathrm{~b}$ & 2.65 & 0.72 \\
\hline
\end{tabular}

Values followed by different letters within a column are significantly different $(P<0.05)$.

$\left.=0.036 ; \mathrm{P}_{2}=0.014\right)$. The concentration of glucose in the overwintering larvae from $P$. tomentosa was significantly higher than that of those from the other two species of trees $(\mathrm{P}<0.05)$. Nevertheless, the trehalose content of the overwintering larvae from $P$. tomentosa was significantly lower than that of those from P. opera and $S$. matsudana $\left(\mathrm{P}_{1}=\right.$ $\left.0.032 ; \mathrm{P}_{2}=0.031\right)$. There were no significant differences in the concentrations of sorbitol and inositol in the larvae collected from the three species of trees.

\section{Protein content}

The protein content of overwintering larvae collected from the three trees was significantly different $(\mathrm{F}=6.25$; $\mathrm{df}$ $=2,8 ; \mathrm{P}=0.034$; Table 4$)$. The concentration of protein in the overwintering larvae from $S$. matsudana $(96.87 \pm 6.80$ $\mathrm{mg} / \mathrm{ml}$ ) was significantly lower than that of those from $P$. opera and $P$. tomentosa $\left(\mathrm{P}_{1}=0.015 ; \mathrm{P}_{2}=0.043\right)$. The content of protein in the larvae from $P$. opera was higher than that of those from P. tomentosa, but not significantly so.

\section{DISCUSSION}

The supercooling point is an important indicator of cold hardiness in insects and is also considered to be the lowest temperature at which an insect can survive. However, large numbers of some insects die at temperatures above their average supercooling point (Masahiko \& Kazuhiro, 1998; Bale \& Hayward, 2010), whereas other insects can survive at temperatures below their average supercooling points (Baust \& Rojas, 1985). The SCPs of the larvae from the different species of hosts differed significantly, which is consistent with previous results, e.g., for Carposina niponensis, Bactrocera dorsalis and Hemiberlesia pitysophila (Ren et al., 2006; Zhong et al., 2009; Wang et al., 2011). Therefore, the species of host tree had a significant effect on the SCP of overwintering larvae of A. glabripennis. The importance of the host in determining the cold resistance of insects is also revealed by host transfer studies; for example, the SCP of Aphis fabae decreases when it switches from feeding on beans in summer to feeding on

Table 3. Concentration $(\mu \mathrm{g} / \mu \mathrm{l})$ of low molecular weight substances in the hemolymph of overwintering larvae collected from three species of trees.

\begin{tabular}{lccccrc}
\hline \multirow{2}{*}{ Host tree } & \multirow{2}{*}{ Number } & \multicolumn{5}{c}{ Concentration $(\mu \mathrm{g} / \mu \mathrm{l})$} \\
\cline { 3 - 7 } & & Glycerol & Glucose & Sorbitol & \multicolumn{1}{c}{ Trehalose } & Inositol \\
\hline P. opera & 3 & $26.58 \pm 1.18 \mathrm{a}$ & $0.047 \pm 0.010 \mathrm{~b}$ & $0.007 \pm 0.001$ & $10.946 \pm 0.879 \mathrm{~b}$ & $0.010 \pm 0.000$ \\
P. tomentosa & 3 & $85.88 \pm 10.67 \mathrm{~b}$ & $0.053 \pm 0.004 \mathrm{a}$ & $0.005 \pm 0.002$ & $5.741 \pm 0.363 \mathrm{a}$ & $0.007 \pm 0.002$ \\
S. matsudana & 3 & $101.96 \pm 24.71 \mathrm{~b}$ & $0.042 \pm 0.012 \mathrm{~b}$ & $0.008 \pm 0.003$ & $10.993 \pm 2.093 \mathrm{~b}$ & $0.016 \pm 0.009$ \\
\hline
\end{tabular}

Values are means $\pm \mathrm{SE}$. Values followed by different letters within a column are significantly different $(\mathrm{P}<0.05)$. 
Table 4. Protein content $(\mathrm{mg} / \mathrm{ml})$ of overwintering larvae collected from three species of trees.

\begin{tabular}{lcccc}
\hline Host tree & Number & $\begin{array}{c}\text { Mean } \pm \mathrm{SE} \\
(\mathrm{mg} / \mathrm{ml})\end{array}$ & $\begin{array}{c}\text { Maximum } \\
(\mathrm{mg} / \mathrm{ml})\end{array}$ & $\begin{array}{c}\text { Minimum } \\
(\mathrm{mg} / \mathrm{ml})\end{array}$ \\
\hline P. opera & 3 & $129.86 \pm 8.84 \mathrm{a}$ & 139.68 & 112.21 \\
P. tomentosa & 3 & $121.98 \pm 4.21 \mathrm{a}$ & 127.83 & 113.79 \\
S. matsudana & 3 & $96.87 \pm 6.80 \mathrm{~b}$ & 109.97 & 87.05 \\
\hline
\end{tabular}

Values followed by different letters within a column are significantly different $(P<0.05)$.

euonymus in autumn and spring (Gash \& Bale, 1985). The cold hardiness of $A$. glabripennis larvae collected in different geographical regions differs (Feng et al., 2014), which might be due to the host plants and temperatures differing in the different regions. Thus, we hypothesized that a primary reason for the differences in population dynamics of A. glabripennis recorded in different areas might be due to their selecting different species of host tree. Based on field studies, the degree of damage to $S$. matsudana caused by $A$. glabripennis is more severe than that to P. opera. Moreover, following field inoculation, the survival of larvae feeding on $S$. matsudana was higher than that of those feeding on $P$. tomentosa. The results of this study indicate that the supercooling capability of the overwintering larvae of $A$. glabripennis that fed on $S$. matsudana was higher than that of those that fed on P. opera and P. tomentosa. Thus, we speculated that this increase in the supercooling capacity might affect host selection by $A$. glabripennis.

Host plant is a major factor determining the accumulation of glycerol and small molecule cryoprotectants, especially in polyphagous insects; which affects the metabolism associated with cold hardiness (Hunter \& McNeil, 1997; Zvereva, 2002). Based on our research, the larvae of A. glabripennis that fed on different species of host trees differed significantly in their protein contents, concentrations of low molecular weight substances and supercooling capacity. The larvae that came from $S$. matsudana had a high supercooling capacity, high total concentrations of low molecular weight substances and low contents of protein. By contrast, the larvae from $P$. opera had a low supercooling capacity, low total concentrations of low molecular weight substances and high contents of protein. These differences may be related to the nutritive quality and levels of secondary substances in the different species of host plant.

In addition, low molecular weight sugars and polyols, including glycerol and trehalose, act as cryo-protective agents in many species of insects during overwintering (Storey \& Storey, 1991; Koštál et al., 2007; Liu et al., 2007, 2009). In this study, larvae from S. matsudana had the highest concentrations of glycerol and trehalose, and lowest SCP. A previous study reports that supercooling is associated with host plants and the concentration of glycerol in H. armigera (Liu et al., 2007). Thus, it is likely that the concentration of glycerol and trehalose are associated with cold resistance. This needs to be confirmed in future studies. Furthermore, the growth and development of $\mathrm{He}$ liothis armigera that feed on different species of host trees differ significantly, which reflects the adaptive strategy of the insect in which the host plants that provide adequate nutrition for insect development also enhance their resistance to adverse environments (Tan \& Zhao, 1990). The results of our study are consistent with previous research in indicating that larvae that came from $P$. opera were lower in body weight, and therefore, this host is not a good host and is likely to result in the development of small adults with a low fecundity.

Based on this study, the species of host tree significantly affected the overwintering larvae of $A$. glabripennis. We only recorded the supercooling points and some of the substances in the overwintering larvae. The associations between survival and the low temperature limits of larvae from different host trees and their cold hardiness strategies are still unclear, mainly because many factors affect the cold hardiness of overwintering larvae of A. glabripennis, such as the nutritional status of the host, developmental stage of the insect and its content of certain substances, among others. Further research is required to clarify how these factors affect the cold hardiness of overwintering larvae and determine the connection between the host plants and the mechanisms of cold resistance. By understanding how P. opera, P. tomentosa, S. matsudana and A. glabripennis interact, we can better understand the cause of outbreaks and forecast the population dynamics of this pest insect in different landscapes in the future.

ACKNOWLEDGEMENTS. The Fundamental Research Funds for the Central Universities (project no. BLYJ201508) and the National Natural Science Foundation of China (grant no. 31300546) supported this study.

\section{REFERENCES}

BALE J.S. \& HAYWARD S.L. 2010: Insect overwintering in a changing climate. - J. Exp. Biol. 213: 980-994.

BAUST J.G. \& RoJAS R.R. 1985: Review - insect cold hardiness: facts and fancy. - J. Insect Physiol. 31: 755-759.

DANKS H. 2006: Insect adaptations to cold and changing environments. - Can. Entomol. 138: 1-23.

Feng Y.Q., Xu L.L., Tian B., Tao J., Wang J.L. \& Zong S.X. 2014: Cold hardiness of Asian longhorned beetle (Coleoptera: Cerambycidae) larvae in different populations. - Environ. Entomol. 43: 1419-1426.

GASH A.F. \& BALE J.S. 1985: Host plant influences on supercooling ability of the black-bean aphid Aphis favae. - CryoLetters 6: $297-304$.

He P. \& Huang J.F. 1992: Artificial feeding of Anoplophora glabripennis. - J. Beijing For. Univ. 14: 61-67.

Hitesaar K., Williams I., Luik A., Metspalu L., Muljar R., Jõgar K., Karise R., Mänd M., Svilponis E. \& Ploomi A. 2009: Factors affecting cold hardiness in the small striped flea beetle, Phyllotreta undulate. - Entomol. Exp. Appl. 131: 278-285.

Hu J.F., Angeli S., Schuetz S., Luo Y.Q. \& HajeK A.E. 2009: Ecology and management of exotic and endemic Asian longhorned beetle Anoplophora glabripennis. - Agric. For. Entomol. 11: 359-375.

Hua L. \& Hua B.Z. 1995: Preliminary study on the host-biotypes of peach fruit borer. - Acta Phytoph. Sin. 22: 165-170.

Hua B.Z., Hua L., Song J.D. \& Dong X.H. 1995: The seasonality and hybridization in Carposina sasakii Matsumura (Lepido- 
ptera: Carposinidae) from different plants. - Acta Univ. Agric. Bor-Occid. 23(5): 2-10.

HunTer M.D. \& MCNEIL J.N. 1997: Host-plant quality in fluences diapause and voltinism in a polyphagous insect herbivore. Ecology 78: 977-986.

JING X.H. \& KANG L. 2002: Research progress in insect cold hardiness. - Acta Ecol. Sin. 22: 2202-2207.

Koštál V., ZahradníčKovÁ H., Šimek P. \& ZelenÝ J. 2007: Multiple component system of sugars and polyols in the overwintering spruce bark beetle, Ips typographus. - J. Insect Physiol. 53: $580-586$.

Li Q., Wang S.Z., Feng C.H., Zhang M., Jiang F., Yang G. \& LuO L.M. 2008: The physiological and biochemical indexes of the cold-hardiness of Locusta migratoria tibetensis Chen. - Acta Ecol. Sin. 28: 1314-1320.

Liu Z., Gong P., Wu K., Wei W., Sun J. \& Li D. 2007: Effects of larval host plants on over-wintering preparedness and survival of the cotton bollworm, Helicoverpa armigera (Hübner) (Lepidoptera: Noctuidae). - J. Insect Physiol. 53: 1016-1026.

Liu Z., Gong P., Heckel D.G., Wei W., Sun J. \& Li D. 2009 Effects of larval host plants on over-wintering physiological dynamics and survival of the cotton bollworm, Helicoverpa armigera (Hubner) (Lepidoptera: Noctuidae). - J. Insect Physiol. 55: 1-9.

Luo Y.Q. \& Li J.G. 1999: Bionomics and occurrence of Anoplophora glabripennis (Motschulsky). - Plant Quarant. 13: 5-7.

MasahiKo W. \& KazUHiRo T. 1998: Adult diapause and cold hardiness in Aulacophora nigripennis (Coleoptera: Chrysomelidae). - J. Insect Physiol. 44: 1103-1110.
OuYang F., Liu Z.D., Yin J., Su J.W., Wang C.Z. \& Ge F. 2011: Effects of transgenic Bt cotton on overwintering characteristics Helicoverpa armigera. — J. Insect Physiol. 57: 153-160.

QIN X.X. \& JIN L.L. 1959: Proceedings of Forest Insects. Scientific Press, Beijing, pp. 252-264.

Ren L., Lu Y.Y., Zeng L. \& Pang S.T. 2006: Effect of different host fruits on the cold hardiness of Bactrocera dorsalis (Hendel) (Diptera: Tephritidae). — Acta Entomol. Sin. 49: 447-453.

SAKURAI H., KAWAI T. \& TAKEDA S. 1992: Physiological-changes related to diapause of the lady beetle, Harmonia axyridis (Coleoptera, Coccinellidae). - Appl. Entomol. Zool. 27: 479-487.

TAN W.J. \& ZHAO H.X. 1990: Changes of sensitivity of cotton bollworms feeding on different host plants to decamethrin. Acta Entomol. Sin. 33: 155-160.

Wang P., Ling F., Yu Y., Zhang A.S., Men X.Y., Li L.L. \& Xu Y.Y. 2011: The dynamics of super-cooling ability and biochemical substances in the overwintering Carposina niponensi Walsingham (Lepidoptera: Carposinidae) larvae. — Acta Entomol. Sin. 31: 638-945.

Zhong J.H., Zhang F.P., Jiang B.F., Xiao M. \& Chen J.H. 2009: Effects of different host pines on the cold tolerance of the pine scale insects. - Sci. Silv. Sin. 45: 100-107.

ZVEREVA E.L. 2002: Effects of host plant quality on overwintering success of the leaf beetle Chrysomela lapponica (Coleoptera: Chrysomelidae). — Eur. J. Entomol. 99: 189-193.

Received October 11, 2015; revised and accepted January 25, 2016 Published online February 15, 2016 